\title{
Leituras
}

A 


\title{
ENTRE EU E O OUTRO \\ uma análise da presenca especular \\ do outro em Borges
}

Devair Antônio Fiorotti

UERR

\begin{abstract}
RESUMO
Este estudo visa discutir a forma como Jorge Luis Borges trabalha a relação entre o eu e o outro, partindo da questão especular. Incomodado pela repetição com que o autor lida com esse tema, analiso as conseqüências de se pensar a separação de um eu que também seria o outro, já que a linguagem é construtora tanto de um quanto do outro.
\end{abstract}

PALAVRAS - CHAVE

Borges. Eu e o outro. Linguagem.

O vidro nos espreita. Jorge Luis Borges

Talvez não seja possível fugir de certa angústia ao lidar com o conceito de alteridade. Afirmações comuns a esse meio geralmente levam-me a um confronto entre aquilo que me vejo sendo, que penso ser, e aquilo que efetivamente sou ou virei a ser. Nesse sentido, torna-se compreensível a relação conflituosa entre Derrida e o gato, tanto o de Alice quanto aquele a olhá-lo nu, em seu quarto. ${ }^{1} \mathrm{O}$ gato, visto como o outro a questioná-lo em sua animalidade: a do gato e a do próprio Derrida. O gato, na linguagem desse autor, possibilita o surgimento da estranheza, daquilo que estava oculto, o outro, que de repente se revela, se vê lá. É na linguagem, dela, por ela, que é possível esse tipo de questionamento, como acentua o próprio Derrida. ${ }^{2}$

Busco enveredar-me por esse campo de estranheza, guiado, num primeiro momento, por Manoel de Barros mas, principalmente, por Jorge Luis Borges. Nesse caminho, procuro identificar e analisar a presença de um construto retórico que tenta estabelecer a presença de outro a partir de um eu. Objetivo instalar-me no centro dessa discussão, norteado pela repetição, na obra de Borges, da presença especular como meio de estabelecer um outro. Este trabalho é a respeito da linguagem poética e algumas de

\footnotetext{
${ }^{1}$ DERRIDA. O animal que logo sou.

${ }^{2}$ DERRIDA. O animal que logo sou, p. 62.
} 
suas possibilidades de imbricamento com o conceito de alteridade. Linguagem que sempre escapa, deixando-nos, como teóricos, como leitores, estranhados. Conceito de estranho que será relacionado à forma como Borges cria um eu e um outro onde, a princípio, teríamos somente o eu.

\section{No PROBlema...}

Diz Manoel de Barros:
Eu sou dois seres.
O primeiro é fruto do amor de João e Alice.
O segundo é letral:
É fruto de uma natureza que pensa por imagens,
Como diria Paul Valéry.
O primeiro está aqui de unha, roupa, chapéu
e vaidades.
O segundo está aqui em letras, sílabas, vaidades
frases.
E aceitamos que você empregue seu amor em nós. ${ }^{3}$

Já de início, Barros se posiciona como dois; dois seres. O primeiro verso instaura a matriz anagramática que guiará a estrutura sêmica do poema: um "eu" é igual a dois. Barros tenta separar um, o filho de João e Alice, do outro, o letral: o que é filho da letra.

No poema, essa tentativa de separar um do outro vai sendo problematizada pelo verbo estar e seu locativo aqui. Enquanto o primeiro está aqui, no texto, no poema, o segundo também está aqui, no poema. Essa estrutura atualiza o paradoxo do primeiro verso: o um que é dois. O "aqui", com esse tipo de construção, pode ainda estar se referindo ao momento em que o poeta está a escrever o poema, contudo essa leitura é questionada por algo inevitável: o único lugar em que os dois estão, com o ato de ler, é no enunciado e no leitor, nesse complexo enredamento criado pela leitura.

Outro relevante aspecto é o processo analógico montado por Barros na busca de deslindar as diferenças entre os dois que são um: "unha" está para "letras", assim como "roupa" está para "sílabas" e "chapéu e vaidades" está para "vaidades frases". Na analogia final, há uma inversão. Nesse arranjo, o primeiro "ser" refere-se ao fruto do amor de Alice e João, agora também personagens textuais, além de sua relação com a biografia do autor; já o segundo, refere-se ao fruto da existência da escrita.

No entanto, o sintagma anagramático da poesia de Barros, em questão, que é o fato do "eu" ser dois, guia a análise a uma estrutura altamente retórica, pois quando o autor tenta separar um do outro, incluindo-os no poema, estabelece-se uma instância figurativa em que duas personagens são estabelecidas. Isso ocorre porque, como Émile Benveniste $^{4}$ e Roland Barthes ${ }^{5}$ destacam, o pronome eu é um instituidor do paradoxo

\footnotetext{
${ }^{3}$ BARROS. Poemas rupestres, p. 45.

${ }^{4}$ BENVENISTE. Problèmes de linguistique générale.

${ }^{5}$ BARTHES. O rumor da língua.
} 
textual, em que sua presença no enunciado escrito, necessariamente, não recupera o enunciador, mas estabelece uma instância discursiva em que ele é criado na linguagem e remete à linguagem. No poema de Barros, o pronome eu é o embreante que abre o poema, e o nós o encerra. Essa estrutura estabelece um caminho do "eu" (o um) ao "nós" (que é dois, no poema).

Nesse ponto, abre-se uma vereda para se pensar a alteridade em sua relação com a linguagem poética, em seu estatuto ficcional, em sua relação com as presenças dos embreantes de primeira pessoa e mesmo com a questão do jogo de personagens. A questão que até esse momento posso articular é a de como afirmar que há um processo de alteridade na linguagem poética se, por um lado, o que temos é uma encenação da linguagem.

\section{O OUTRO, O MESMO}

Vejo Jorge Luis Borges como um mestre em problematizar a relação do artista com sua obra, num jogo de linguagem. Isso pode ser visto no título do livro de poemas O outro, o mesmo, ${ }^{6}$ ou como no conto intitulado "O outro". ${ }^{7}$ Nesse conto, Borges se inclui como personagens. ${ }^{8}$ Como personagens, no plural, porque são criados dois Borges, que estão ali, nas palavras enigmáticas do autor, um sonhando e o outro na vigília. ${ }^{9}$ Como acentua Borges, eles eram demasiado diferentes e parecidos e não poderiam enganar um ao outro. ${ }^{10}$ Eles se apresentam num momento de fidelidade e angústia. A princípio, temos uma instância instalada de um eu, o Borges narrador, até um outro, um terceiro, que seria outro Borges.

Num texto sobre a constituição do sujeito no Ocidente, após uma incursão histórica, Marcel Mauss declara: "não lhes falarei da questão lingüística que seria necessário abordar, para fazer o trabalho [de análise] completo [da noção de 'eu']". ${ }^{11} \mathrm{O}$ fato lingüístico diz respeito destacadamente à questão da relação desse sujeito com a linguagem. Esse indício é encontrado posteriormente ao recalque mencionado. $\mathrm{O}$ autor alude à relação dos indivíduos com os pronomes, com o "eu-mim". ${ }^{12}$ Fala, principalmente, da problemática residente entre "o sujeito que fala e o objeto de que fala". ${ }^{13} \mathrm{O}$ pensador conclui de forma paradoxal, aparentemente assustado com as possíveis conseqüências de suas proposições: “a palavra 'mim' é onipresente e, entretanto, não se exprime pela palavra 'mim' e nem pela palavra 'eu'. Porém no vasto domínio da língua sou bisonho. [E encerra:] Minha pesquisa será totalmente uma pesquisa de direito e de moral". ${ }^{14}$

\footnotetext{
${ }^{6}$ BORGES. Obras completas, v. 2. As traduções usadas por mim aqui foram confrontadas com o original, principalmente pelo site sololiteratura: literatura hispanoamericana.com.

${ }^{7}$ BORGES. Obras completas, v. 3.

${ }^{8}$ BORGES. Obras completas, v. 3, p. 10.

${ }^{9}$ BORGES. Obras completas, v. 3, p. 15.

${ }^{10}$ BORGES. Obras completas, v. 3, p. 14.

${ }^{11}$ MAUSS. Sociologia e antropologia, p. 211.

${ }^{12}$ MAUSS. Sociologia e antropologia, p. 211.

${ }^{13}$ MAUSS. Sociologia e antropologia, p. 211.

${ }^{14}$ MAUSS. Sociologia e antropologia, p. 211.
} 
O paradoxo de um "mim" que não é possível de se exprimir com um "mim" nem com um "eu" aponta para o centro da problemática deste artigo: o estabelecimento de um outro que é um mesmo, ao mesmo tempo em que se diferencia da pessoa pelo estatuto literário. Mauss anuncia justamente a existência de um abismo entre o sujeito que fala e seu estabelecimento pela e na linguagem.

Borges se indaga no "Poema dos dons":

Qual de nós dois escreve este poema

De uma só sombra e de um eu plural?

O nome que me assina é essencial

Se é indivisso e uno esse anátema? ${ }^{15}$

A primeira pergunta localiza uma relação conflituosa no poema: uma só sombra, mas que é problematizada pelo poeta como possuidora de um eu plural. Há um nós ainda a abrir o questionamento, indicando que o poeta não seria uno, além da dúvida a respeito de quem estaria a escrever o poema. Na segunda interrogativa, ele se pergunta a respeito de quem assina o poema, se ele seria essencial - com isso imutável.

O nome que assina é visto como um "anátema”, uma expurgação, uma condenação. Essa palavra, oriunda do meio sacro, aponta para o nome como uma prisão, a prender esse nós, como fruto do gládio existente em quem escreve o texto e deve abandoná-lo como objeto. Na perspectiva lingüística, um Borges que não está como indivíduo ali presente. Resta o nós: um indivíduo e a linguagem com suas possibilidades, eu, mim, nós. Isso num âmbito provisório e insustentável já que, como apontarei no final, a linguagem cria também o indivíduo.

Borges se coloca na posição do outro: "Sinto às vezes com vago horror sagrado / que sou o outro, o morto, habituado / Aos mesmos passos e nos mesmos dias." 16 O outro é localizado nesse ponto com um distanciamento. Mas, o que mais chama atenção nos versos é o estado em que o poeta se diz encontrar "com vago horror sagrado". A palavra sagrado possui uma reverberação no poema: é a palavra "anátema". Ambas lembram o sacro: a primeira é modificada pela palavra horror; já anátema, por si só, remete ao horror, ao que foi excomungado no âmbito sagrado. O que pode estar causando o horror sacro é o fato de o poeta se ver também como esse outro, morto, habituado aos mesmos passos.

Percebo no texto de Borges uma relação abismática entre o eu e o outro, esse nós. A palavra nós, esse embreante, não resolve a questão levantada por Borges; ao contrário, ela camufla o conflito. As perguntas são lançadas e não há uma resposta (pelo menos eu não as reconheço). Fica no ar, ou melhor, no texto, a angústia desse vazio.

Esse abismo levantado por Borges pode ser posto a dialogar com a problemática moderna em relação aos marcadores discursivos, concernentes à linguagem e sua referencialidade/não-referencialidade. Em outras palavras, tanto Borges quanto Mauss anunciam a problemática da relação do sujeito com sua representação e com sua criação pela e na linguagem; sujeito que se relaciona, ainda, a um ser biológico. Mauss traz à

\footnotetext{
${ }^{15}$ BORGES. Obras completas, v. 2, p. 208.

${ }^{16}$ BORGES. Obras completas, v. 2, p. 208.
} 
tona a questão de um sujeito que se vê, de alguma forma, representado por um marcador eu. Borges problematiza também essa relação, incluindo-se como um eu e como um outro, a princípio sendo o mesmo.

Contudo, defendo que, em Borges, temos personagens (o eu e o outro: nós) assim como se apresentam em Manoel de Barros. Isso se deve à grande encenação criadora que a literatura representa. Há esse logos, como em João, ${ }^{17}$ criando todas as coisas. É em sentido similar que Barthes anuncia, baseado na psicanálise, a existência de um sujeito sustentado "por uma sucessão de linguagens". ${ }^{18}$ É esse caráter linguageiro da existência humana que vejo representado nos textos de Borges e de Barros, apontando para o aspecto constitutivo do que há de mais humano: sua constituição pela e como linguagem.

Borges joga com essas possibilidades da linguagem, questionando a organização da identidade autoral, bem como a existência da alteridade no arranjo das personagens. Em situação análoga ao poema de Barros, ele diz em "Borges e eu":

Ao outro, a Borges, é que sucedem as coisas. Eu caminho por Bueno Aires e me demoro, talvez já mecanicamente, para olhar o arco de um vestíbulo e o portão gradeado; de Borges tenho notícias pelo correio e vejo seu nome em uma lista tríplice de professores ou em um dicionário biográfico. ${ }^{19}$

A relação de identidade presente no texto, entre o um que é ao mesmo tempo o outro, leva a uma dimensão de estranhamento. Tal estranhamento encaminha a um estado de horror, como aponta o texto de Borges. Desta forma é concluída essa última narrativa do poeta: "Não sei qual dos dois escreve essa página." ${ }^{20} \mathrm{Na}$ realidade, nenhum dos dois escreve o texto; eles estão e são escritos nele. Com muita liberdade interpretativa, digo que o sujeito biológico Borges é "anatemado" do texto, com o abandono que a escritura provoca.

No poema, a palavra anátema refere-se ao "nome que me assina", que Borges se pergunta se é essencial, imutável. Ponto fulcro é a localização objetival na qual o poeta se inscreve: é o nome que o assina, não o contrário. $O$ nome próprio, por excelência, remete ao caráter volátil, acoplador da linguagem, seu caráter arbitrário, para lembrar Saussure. Metonimicamente, o nome remete à linguagem. Não escolhemos o nome; como uma cicatriz, uma imposição, somos levados por ele. Os significados vão se acoplando ao nome próprio e, geralmente de modo impositivo, somos representados por ele, nele.

Nesse sentido, "anátema" pode ser visto no poema como aquilo que expurga a complexidade aludida pelo texto de Borges, causando horror: o nome, paradoxalmente, dá e não dá conta do sujeito. Ao mesmo tempo em que o nome "Jorge Luis Borges" dá conta da multiplidade de um e um outro no poema (é esse o nome que o assina), o próprio texto questiona essa capacidade de representação.

\footnotetext{
${ }^{17} \mathrm{JOÃO} 1,1$.

${ }^{18}$ BARTHES. O rumor da língua, p. 41.

${ }^{19}$ BORGES. Obras completas v. 2, p. 206.

${ }^{20}$ BORGES. Obras completas v. 2, p. 206.
} 


\section{O estranho de Freud e o outro de Borges}

Num texto de 1919, Freud discute o Unheimlich, traduzido para a língua portuguesa por estranho. O estranho estaria relacionado com o que é assustador, com o que provocaria medo e horror. ${ }^{21}$ Seria "aquela categoria do assustador que remete ao que é conhecido, de velho, e há muito familiar". ${ }^{22}$ O centro da discussão de Freud estaria em mostrar como o familiar revela-se o oposto, o estranho, o não familiar.

Ponto importante da argumentação freudiana é a possibilidade de ter o oposto de Unheimlich, isto é, Heimlich, familiar, significando o que se faz às escondidas, o que é secreto. ${ }^{23}$ Com isso, percebe-se uma coincidência de sentido entre termos que, a priori, teriam sentidos opostos: Heimlich e Unheimlich. Segundo Schelling, Unheimlich seria o nome de tudo que deveria ter permanecido secreto, oculto, mas que viria à luz. ${ }^{24}$

$\mathrm{Na}$ modernidade, quando pensamos a presença do outro, principalmente enquanto uma organização textual literária, como em Borges, não raramente nos deparamos justamente com uma instância causadora de uma espécie de desamparo, levando ao que foge à compreensão imediata, pois o estranho surgiria de algo familiar ao indivíduo. ${ }^{25}$ Ele surgiria de algo como o outro em Borges que, de alguma forma, é o mesmo; como o caminho de linguagem proposto por Barros de um eu até um nós.

Maria Inês França, discutindo o Unheimliche freudiano, ressalta o duplo como meio propulsor para o surgimento do estranho, o momento em que a coincidência da repetição de algo suscitaria angústia. Diz ela que a angústia é "o motor inquietante de uma ameaça anônima, impossível de suprimir". ${ }^{26}$ E o estranho surgiria, por exemplo, quando a imagem do duplo se revelasse ao indivíduo, como uma imagem no espelho.

A relação de Borges com o espelho é conflituosa, parecida com a relação de conflito entre o eu e o outro. Em "O espelho", ele diz:

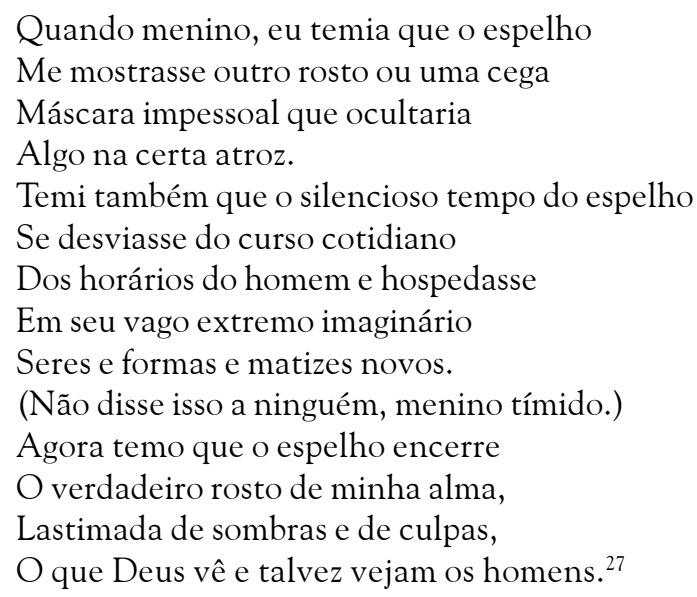

\footnotetext{
${ }^{21}$ FREUD. Edição standard brasileira das obras completas de Sigmund Freud, v. 17, p. 237.

${ }^{22}$ FREUD. Edição standard brasileira das obras completas de Sigmund Freud, v. 17, p. 238.

${ }^{23}$ FREUD. Edição standard brasileira das obras completas de Sigmund Freud, v. 17, p. 241.

${ }^{24}$ FREUD. Edição standard brasileira das obras completas de Sigmund Freud, v. 17, p. 242.

${ }^{25}$ FREUD. Edição standard brasileira das obras completas de Sigmund Freud. v. 17, p. 262.

${ }^{26}$ FRANÇA. Psicanálise, estética e ética do desejo, p. 77.

${ }^{27}$ BORGES. Obras completas, v. 3, p. 211.
} 
Nesse poema, desde a infância, o poeta lida com o espelho de modo não muito pacífico. A palavra outro apresenta o medo de se deparar com um rosto diferente do conhecido. Um rosto que, paradoxalmente, é e não é o mesmo, sendo a imagem refletida. É a luz criadora que orienta a reflexão e o assusta. Refletir encaminha a um olhar para trás e, de repente, a um encontro com a alma "lastimada de sombras e de culpas". Depois, o medo aterrorizador de se ver revelado enquanto alma, de tê-la ali tão familiarmente vislumbrada. No espelho, a imagem que olha é olhada, a princípio, pelo mesmo. Tão diferentes e iguais como as palavras Heimlich e Unheimlich. Ora, o medo desse outro que é o mesmo está nitidamente em consonância com a idéia freudiana do estranho.

Nesse contexto, o estranho seria o próprio familiar, a sua re-velação. Essa experiência do estranho seria "a suspensão do juízo de existência e da prova de realidade". ${ }^{28}$ Poucas coisas talvez sejam tão irreais como a nossa imagem no espelho. Como num oximoro, há um choque, de forma muito complexa: o eu e o outro que são o mesmo. De forma borgeana, diante do espelho, perderíamos nossa relação familiar com o mundo, pois o estranho emergiria do familiar. Seria algo que não poderia ser visto, mas que seria visto, levando à angústia ou ao horror sagrado, para usar as palavras de Borges. O desconhecido seria conhecido e estaria ali, usando o termo da psicanálise, recalcado.

Quando penso a relação dessa instância do familiar que causaria estranhamento em relação à organização da linguagem poética, vislumbro um caminho profícuo de entendimento para o jogo estabelecido por Barros e, mais incisivamente, por Borges: talvez a linguagem seja a coisa mais familiar a nós humanos: somos estabelecidos por ela em seu poder criador. Ao mesmo tempo, o que a linguagem poética vem estabelecer, lembrando esse poder criador, é a dimensão de criatura à qual pertencemos na ordem do discurso. Cria-se um outro, um mesmo, um terceiro Borges. Cria-se um eu que é fruto de um outro eu e que forma um nós, que não diz muita coisa a respeito do que efetivamente se é.

\section{UM EU OUTRO DO TEXTO}

Principalmente a forma central com que nos apresentamos num texto (tanto o poeta, seu outro, seu eu: eu) remete a uma complexa instância discursiva. O "eu", por exemplo, é ao mesmo tempo eu, escritor deste texto, como tu, eu leitor do texto. Bem como, é todos os eus existentes, simultaneamente. Esses marcadores discursivos são embreantes, "uma classe de palavras cujo sentido varia de acordo com a situação; como tais palavras não têm referência própria na língua, só recebem um referente quando estão incluídas numa mensagem". ${ }^{29}$

A existência de um sujeito de primeira pessoa desinencial remeteria anaforicamente, a princípio, a um nome presente no texto ou, se tivéssemos diante do elaborador do texto, ouvindo-o pronunciá-lo, remeteria deiticamente a tal elaborador. No poema, geralmente não existe o nome presente no texto; quase sempre, somente na capa, contracapa; ao mesmo tempo em que não estamos diante do criador do texto a pronunciá-lo. Como destaca Dominique Maingueneau,

\footnotetext{
${ }^{28}$ FRANÇA. Psicanálise, estética e ética do desejo, p. 76.

${ }^{29}$ DUBOIS et al. Dicionário de lingüística, p. 208.
} 
O leitor de um romance, de um poema, o espectador de uma peça de teatro não têm contato com o sujeito que escreveu o texto, a pessoa do autor. Não somente por razões materiais, mas sobretudo porque é da essência da literatura não pôr em contato o autor e o público senão através da instituição literária e de seus rituais. ${ }^{30}$

Ressalvando a literatura oral, como a dos cantadores nordestinos, o autor toca em algo simples, mas essencial, da recepção dos textos literários: a ausência do autor no ato da leitura. A leitura de um texto literário está inserida num âmbito ritualístico próprio de seu objeto. Nessa propriedade, por esse tipo de ausência, ele comunica, porém, "pervertendo as regras do intercâmbio lingüístico". ${ }^{31}$

Essa perversão diz respeito principalmente ao fato de o texto literário construir suas cenas enunciativas por meio de um jogo de imbricações internas ao próprio texto. ${ }^{32}$ Contudo, no caso do poema de Barros e das citações de Borges, é possível recuperar de forma dêitica o referente para desinências de primeira pessoa de um texto poético. Com essa recuperação, geralmente resta, como referente, a presença de um nome próprio na capa e uma inacessível ausência, incomensurável, não encarnável. Essa ausência relaciona-se principalmente à perversão relativa ao intercâmbio lingüístico. No poema de Barros, como embreante, essa marcação desinencial de primeira pessoa não aponta para fora do texto mas, como já mostrado com Barthes, para uma coerência interna.

O "eu", num texto poético, leva-nos a novas dimensões. É um "eu" que tenta dar conta da presença, da existência do nome de autor na capa e que se acopla ao leitor. Pervertendo a própria gramaticalidade da língua portuguesa, o leitor somos um "mim" que se julga desconhecedor. Barthes diz que residiria um escândalo nesse tipo de organização: "o pronome, por exemplo, que é sem dúvida o mais vertiginoso dos shifters, ${ }^{33}$ pertence estruturalmente (insisto) à fala". ${ }^{34}$ No poema, o "eu" pertence à escrita, não mais à fala. No poema escrito, não temos um falante, mas um enunciado e um leitor impossibilitado de ter consigo o emissor do poema. No entanto, o significante eu se presencia no texto independente da presença do emissor, inclusive no texto do próprio Barthes e de Mauss.

Diz Barthes que "o sujeito da enunciação nunca pode ser o mesmo que agiu ontem". ${ }^{35}$ Nesse sentido, o sujeito da enunciação se atualizaria num presente e sempre num presente com a leitura. Com isso, se ele só existe nesta atualização da leitura, só existe no ato de ler. Barthes conclui, afirmando que "o eu do discurso já não pode ser o lugar onde se restitui inocentemente uma pessoa previamente guardada". ${ }^{36} \mathrm{O}$ advérbio inocentemente, nesse contexto, traz um pressuposto esclarecedor ao texto bartheano: a questão não é que não se possa restituir, por exemplo, um "eu" ao referente-nome na capa de um livro. Isso pode ser feito, só que não inocentemente.

\footnotetext{
${ }^{30}$ MAINGUENEAU. Elementos de lingüística para o texto literário, p. 16.

${ }^{31}$ MAINGUENEAU. Elementos de lingüística para o texto literário, p. 16.

${ }^{32}$ MAINGUENEAU. Elementos de lingüística para o texto literário, p. 16.

${ }^{33} \mathrm{O}$ mesmo que embreante.

${ }^{34}$ BARTHES. O rumor da língua, p. 24. Com itálicos e comentário entre parênteses no original.

${ }^{35}$ BARTHES. O rumor da língua, p. 20.

${ }^{36}$ BARTHES. O rumor da língua, p. 20.
} 
Principalmente, não se pode fazer isso inocentemente porque o "eu" presente numa leitura, a priori, é preenchido pelo antes "tu" e agora "eu" leitor. Outro problema é que, mesmo restituindo o "eu" ao nome próprio presente na capa, esse nome é uma criação da existência da obra de arte. Muitas vezes, é um "eu" a dialogar com o indivíduo, a dialogar com o nome na capa, instaurando um tipo diferenciado de intertextualidade, uma intertextualidade biográfica. No caso específico de Borges, podemos falar de uma intertextualidade biobibliográfica, enraizada destacadamente numa cultura livresca.

\section{DIANTE DO OBSCENO}

Em outro poema intitulado "Os dons", Borges enumera várias coisas (música, amor, infâmia, a linguagem, etc.) que a nós teriam sido ofertadas, e principalmente a ele. Pelo menos, é esse o entendimento que tenho a partir do final do poema: "Foi digno do sabor de cada dia; esta é a tua história, e a minha, todavia." ${ }^{37}$ Disse principalmente a ele, porque o final do poema é extremamente ambíguo. O embreante tua remete a mim leitor, mas também à instância outra do próprio Borges, já analisada no "Poema dos dons" e mesmo em "Borges e eu". Nessa ambigüidade, ele pode estar referindo-se à relação Borges e eu, em que um eu se vê também como outro. Ao mesmo tempo, como leitor, há o Borges criador do texto, e esse eu pode ser o leitor exercendo seu papel subversor, principalmente pelo caráter escandaloso do pronome eu.

A estrofe localizada no centro do poema "Os dons" diz:

Foi-lhe dada a linguagem, essa mentira,

E foi a carne - argila - outro desvelo;

Foi-lhe dado o obsceno pesadelo

E, no cristal, o outro, o que nos mira. ${ }^{38}$

Nessa estrofe, algo me chama muito a atenção: o aposto "essa mentira" a relacionarse com a palavra linguagem. Apesar de ser vista como "mentira", a linguagem foi dada com desvelo, com cuidado, carinho. Isso denuncia a palavra outro, no segundo verso. Mas, mentira, a priori, não é vista como algo positivo. Ela é geralmente estigmatizada. Com isso, a linguagem entra no poema como algo diferente da verdade, com uma carga não muito atraente.

$\mathrm{Na}$ estrofe, pelo caráter negativo da palavra mentira, ela se comunica anagramaticamente com a palavra pesadelo e, também, com a adjetivação dessa palavra: obsceno. Borges não nos diz que pesadelo é esse, mas como desenvolve Vicentini de Azevedo, ${ }^{39}$ "obsceno" lembra aquilo que está fora de cena. É possível vislumbrar, no poema, uma inferência ao obsceno inconsciente. A palavra pesadelo trabalha metonimicamente com o mundo do sonho. O inconsciente que o pesadelo re-vela, interpreta, possui o seu outro, o consciente: o domínio mais comum da linguagem humana. Talvez esse caminho

\footnotetext{
${ }^{37}$ BORGES. Obras completas, v. 3, p. 464.

${ }^{38}$ BORGES. Obras completas, v. 3, p. 463.

${ }^{39}$ AZEVEDO. A metáfora paterna na psicanálise e na literatura.
} 
de análise não seja tão insólito, principalmente se levarmos em conta a última estrofe do poema "Os espelhos":

\section{Deus inventou as noites que se armam \\ De sonhos e as formas do espelho \\ Para que o homem sinta que é reflexo \\ E vaidade. Por isso nos alarmam..$^{40}$}

Nessa estrofe, "as noites", como sujeito, "se armam". Observe o vocabulário oriundo do mundo belicoso, das guerras. Mais revelador é o que se segue: as noites se armam de sonhos e as formas do espelho. Os sonhos, aqui, são nitidamente uma inferência metonímica ao inconsciente, como coisas que se pertencem. A mesma relação é feita com espelho. Ambos apontam para o mundo do reflexo, da existência assustadora do outro. Tanto o sonho quanto o espelho possibilitam que o outro surja. Talvez, para Borges, surja o desconhecido do eu, tão perseguido pelo poeta. O final da estrofe é mais revelador ainda e aponta para o estranho freudiano. O estranho que é familiar e, por isso, causa angústia ou, em Borges, alarma, aciona a sineta para o que efetivamente seríamos.

No último verso da estrofe já citada, está novamente lá: o outro, no cristal, que nos mira. Jorge Luis Borges insiste no espelho; é possível ler essa repetição. Ela não traz tranqüilidade mas, como algo do âmbito do pesadelo, aponta para um desdobramento do eu para o âmbito do outro, o que a imagem especular propiciaria. $\mathrm{O}$ estranho que está a se repetir no texto de Borges, essa possibilidade da reflexão que o espelho aciona, esse outro, não é algo distante, mas é paradoxalmente sua imagem. É com o espelho, e também com o sonho, que estamos diante da possibilidade do reflexo. A imagem no espelho indica, em Borges, a presença do outro, pois "se entre as quatro / Paredes do quarto existe um espelho, / Já não estou sozinho". ${ }^{41}$ Contudo, como indica o conto "O aleph", parece que esse outro assusta mais como uma possibilidade de encontro do que a vivência efetiva dessa impossibilidade, já que estamos falando de um desdobramento do eu para um outro. Diz o poeta no conto: "vi todos os espelhos do planeta e nenhum me refletiu". ${ }^{42}$

O olhar do gato incomoda Derrida e incomoda, ainda, o leitor do texto que se depara também sendo visto pelo animal. Que animal é esse? O próprio Derrida responde: "Que animal? O outro." ${ }^{43}$ Não podemos esquecer que o olho funciona de modo especular. É um espelho a refletir quem imagina estar somente olhando. Derrida está refletido no olhar do animal, onde o gato se apresenta como aquele que instaura o outro. Vejo o outro do texto de Borges de modo análogo a esse outro apontado por Derrida. É um outro possuidor de uma verdade assustadora. Aquilo que representaria a identidade, o eu, é questionado pela presença desse outro que é e não é o mesmo.

\footnotetext{
${ }^{40}$ BORGES. Obras completas, v. 2, p. 214.

${ }^{41}$ BORGES. Obras completas, v. 2, p. 214.

${ }^{42}$ BORGES. Obras completas, v. 3, p. 695.

${ }^{43}$ DERRIDA. O animal que logo sou, p. 15.
} 
Ao mesmo tempo, esse imbricamento só pode ser pensado pela linguagem. É óbvia essa afirmação. Contudo, é a própria linguagem que estabelece o pensamento, que estabelece o eu e o outro, seja ele o olhar do gato ou mesmo a repetição especular do outro em Borges. Nesse sentido, tanto o eu quanto o outro estão e são, na linguagem humana. É nessa direção que me questiono, após ter sido literalmente passado pela linguagem de Borges neste texto. Pensar a relação moderna de alteridade, da presença do outro, não pode ignorar essa instância linguageira que o texto poético insiste em denunciar.

No caminho que leva ao outro, está a linguagem. Mais que isso: ela estabelece o próprio caminho. Os embreantes, como o eu, lembram essa dimensão. Mauss não se assustou por algo irrelevante. Ele anunciou justamente que do eu até o mim há um longo caminho a ser percorrido, um caminho de linguagem; um caminho de alteridade. Talvez esse seja um bom entendimento para a insistência de Borges em, no mínimo, problematizar a existência desse mim, que a presença do outro especular, ou do inconsciente, denuncia.

Dessa relação complexa, surge um estranho, esse outro Borges. Surge problematizando os textos analisados, porque ele está imbricado com o mais familiar: o outro Borges que é o mesmo. Na realidade, segundo Freud, esse estranho é o próprio familiar que se re-vela. Nesse caminho, o outro do espelho causa angústia porque se apresenta em sua familiaridade, ocultado justamente por ser o que há de mais familiar. Como seres culturais estabelecidos pela linguagem, na linguagem, somos frutos dela. A literatura (com seus eus, seus outros) é, num âmbito de linguagem, assim como o autor, esse outro que também sou, que agora se funda.

\title{
4.
}

\begin{abstract}
A B S TR ACT
This study aims at discussing the means through which Jorge Luis Borges works the relation between the "I and the other", based on issues about specular images. Bothered by the repetition of this theme in the author's works, I analyze the consequences of thinking the separation of an "I" that would also be "the other", considering the fact that language constructs both one and the other.
\end{abstract}

\section{KEYWORDS}

Borges. I and the other. Language.

\section{REFERÊNCIAS}

AZEVEDO, Ana Vicentini. A metáfora paterna na psicanálise e na literatura. Brasília: Edunb; São Paulo: Imprensa Oficial, 2001.

BARROS, Manoel. Poemas rupestres. Rio de Janeiro; São Paulo: Record, 2004.

BARTHES, Roland. O rumor da língua. 2. ed. Trad. Mario Laranjeira. São Paulo: Martins Fontes, 2004.

BENVENISTE, Émile. Problèmes de linguistique générale. Paris: Gallimard, 1997. v. 1. 
BÍBLIA SAGRADA. N. T. Edição trilíngüe (grego, português, inglês) organizada por Luiz Alberto Teixeira Sayão. São Paulo: Vida Nova, 1998.

BORGES, Jorge Luis. Atlas. In: . Obras completas. Vários tradutores. São Paulo: Ed. Globo, 1998/1999. v. 3.

BORGES, Jorge Luis. História da noite. In: . Obras completas. Vários tradutores. São Paulo: Ed. Globo, 1998/1999. v. 3.

BORGES, Jorge Luis. O fazedor. In: . Obras completas. Vários tradutores. São Paulo: Ed. Globo, 1998/1999. v. 2.

BORGES, Jorge Luis. O livro de areia. In: . Obras completas. Vários tradutores. São Paulo: Ed. Globo, 1998/1999. v. 3.

BORGES, Jorge Luis. O outro, o mesmo. In: . Obras completas. Vários tradutores.

São Paulo: Ed. Globo, 1998/1999. v. 2.

SOLOLITERATURA: literatura hispanoamericana.com. Disponível em: $<$ http://sololiteratura.com >. Acesso em: 2 jul. 2008.

DERRIDA, Jacques. O animal que logo sou. Trad. Fábio Landa. São Paulo: UNESP, 2002. DUBOIS, Jean et al. Dicionário de lingüística. 8. ed. Trad. Frederico Pessoa de Barros et al. São Paulo: Cultrix, 2001.

FRANÇA, Maria Inês. Psicanálise, estética e ética do desejo. São Paulo: Perspectiva, 1997. FREUD, Sigmund. O estranho. In: . História de uma neurose infantil e outros trabalhos. Trad. do alemão e do inglês sob a direção de Jayme Salomão. Rio de Janeiro: Imago, 1976. p. 275-314. (Edição standard brasileira das obras completas de Sigmund Freud, 17).

MAINGUENEAU. Elementos de lingüística para o texto literário. Trad. Maria Augusta de Matos. São Paulo: Martins Fontes, 1996.

MAUSS, Marcel. Sociologia e antropologia. Trad. Lamberto Puccinelli. São Paulo: EPU e EdUSP, 1974. 